\title{
Influencing adherence to physical activity behaviour change in obese adults
}

\author{
By Erik Hemmingsson, Angie Page, Kenneth Fox and Stephan Rössner
}

\begin{abstract}
Objective: Regular physical activity has beneficial health effects and aids weight management in obese adults, yet satisfactory adherence to physical activity behaviour change is rare. The primary objective was to summarise research evidence concerning influences on long-term physical activity behaviour change in obese adults. Secondary objectives were to scrutinise study quality, and to present recommendations for future research in terms of study design and research areas.

Design: Narrative review. Papers were identified from a comprehensive electronic and manual literature search, and included/excluded according to set inclusion/exclusion criteria. Data from included studies was extracted and summarised.

Results: Negative influences were social physique anxiety, unrealistic activity messages, and low motivation. Positive influences included social support, activity self-monitoring, increased activity-specific self-efficacy, moderate intensity activities (40-70\% of $\mathrm{V}_{2}$-max), moderate activity volumes (2-3 hours/week), short-bout sessions (10-15 minutes) with treadmill access, and home-based physical activity. However, limited strength and volume of evidence or inconclusive findings reduced our confidence in several purported influences.

Conclusions: Many factors appear to influence adherence to physical activity behaviour change in obese adults. Although information on influences is accumulating, more research is still needed on how to provide best therapeutic support for this challenging task.

Keywords: Adherence, adults, behaviour change, exercise, physical activity, obesity
\end{abstract}

\section{Introduction}

Obesity (defined as having a body mass index (BMI) above 30 $\mathrm{kg} / \mathrm{m}^{2}$ ) is now recognised as a global epidemic (1). Health risks of obesity include type 2 diabetes, hypertension, cardiovascular disease and some cancers (2), and obesity also inflicts serious social and psychological penalties (3). Regular physical activity, i.e. any bodily movement produced by skeletal muscles that results in energy expenditure (4), is inversely related to longterm weight gain (5). Physical activity coupled with dietary restrictions produces greater weight loss compared to diet alone (6). Physical activity also improves mental well-being (7), appetite regulation and macronutrient intake balance (8), and increases cardiorespiratory fitness (9). (See Rissanen and Fogelholm (10) for more detailed information on physical activity in the treatment and prevention of obesity co-morbidities). However, whilst there is considerable evidence as to the many beneficial effects of physical activity in obese adults, approaches to facilitating long-term increases in physical activity, and the subsequent attainment of those beneficial effects, are relatively little researched. Indeed, many aspects of adherence to physical activity behaviour change are not yet known in normal-weight (BMI 20-25 kg/m²) populations.

The primary objective of this narrative review paper was to summarise best available evidence on influences on physical activity behaviour change adherence in obese adults. Secondary

Erik Hemmingsson ${ }^{1,2} *$, PhD-student, Angie Page ${ }^{1}, \mathrm{PhD}$, Kenneth Fox ${ }^{1}$ Professor, Stephan Rössner ${ }^{2}$, Professor

${ }^{1}$ Department of Exercise and Health Sciences, University of Bristol, UK

${ }^{2}$ Obesity Unit M73, Karolinska Institutet at Huddinge University Hospital, Sweden

Correspondence: Erik Hemmingsson, University of Bristol, Dept of Exercise and Health Sciences, Priory House, 8 Woodland Rd., Bristol BS8 1TN, Avon, UK. Current address: Obesity Unit M73, Karolinska Institutet, Huddinge University Hospital, SE-141 86 Stockholm, Sweden

E-mail: erik.hemmingsson@bristol.ac.uk objectives were to give an indication of our confidence in the reviewed evidence by scrutinising study design quality, and to present recommendations for future research in terms of study design and research areas.

\section{Methodology \\ Literature search}

Both electronic and manual searches were carried out to identify all studies relevant to the primary review objective. The electronic searches used Medline (1966-present) and BIDS Embase (1980-present) using synonyms of "physical activity", "exercise", "obesity", "adherence", "influence", "promotion", "mediate", "treatment", and "behaviour change". The manual searches concerned going through the reference lists of previously included studies that had been identified from the electronic searches.

\section{Inclusion and exclusion criteria}

Given the study's primary objective, we elected to include any study with information on factors that influenced physical activity behaviour change adherence, both from a positive and negative point of view. We excluded those studies that did not report any aspects of physical activity behaviour change. Attempts were made to restrict our review to papers where the mean BMI of the study populations was above $30 \mathrm{~kg} / \mathrm{m}^{2}$, but a few studies on overweight (BMI $25-30 \mathrm{~kg} / \mathrm{m}^{2}$ ) adults were included in areas where important information was lacking on obese samples.

\section{Data extraction and presentation}

Relevant data from included studies was extracted and narratively summarised using separate sections for different influence types, including social, behavioural, cognitive, environmental, 
and bout adaptational influences. The final section contains, along with suggestions for future research, a critical review of the design and presentation of long-term ( $>1 \mathrm{y}$.) physical activity intervention studies, and serves to give an indication of our confidence in the reviewed evidence.

\section{Cognitive influences on physical activity adherence \\ Activity specific self-efficacy}

One of the most potent and frequently mentioned psychological mediators of successful behaviour change is self-efficacy (11), although this has not been well researched in the context of physical activity and obesity. Self-efficacy is highly situational, i.e. one can have high self-efficacy for weight training and, conversely, low self-efficacy for aerobic dance. McAuley et al. (11) found that previously sedentary (no regular involvement in physical activity regimes in the previous 6 months), middle-aged (45-64 years of age) adults significantly improved adherence to a 20 -week walking programme (in this case session attendance) with a relatively simple information programme, specifically aimed at increasing self-efficacy. As stipulated by Social Cognitive Theory (12), self-efficacy is increased by success, and when a sense of expertise and competence is developed. McAuley et al. (11) found that self-efficacy enhancement was particularly important in the early phases of behaviour change, and less important as physical activity become less psychologically demanding.

Probably the only study to date to evaluate self-efficacy and other psychological outcomes for physical activity in an obese sample was Pinto et al. (13), who investigated changes in selfefficacy and decisional balance (perceived pros minus perceived cons of changing behaviour). Thirty-two severely obese women (BMI $41.2 \mathrm{~kg} / \mathrm{m}^{2}$; age $43 \mathrm{y}$.) underwent a multi-disciplinary weight management programme, including strategies to increase exercise involvement and an individualised exercise prescription. A twelve-week follow-up revealed that activity levels had significantly increased from $43.8 \mathrm{~min} /$ week to $144.3 \mathrm{~min} /$ week $(\mathrm{p}<0.01)$, with a concomitant $14 \%$ improvement of exercise selfefficacy scores. Exercise decisional balance did not change during the study. Although too short to reveal effects on the maintenance of activity levels, protocol inclusion of similar psychosocial outcome measures may provide crucial insight into behaviour change response magnitude and duration (process evaluation), which would increase understanding into why interventions work/do not work satisfactory.

\section{Social physique anxiety}

Perceived disapproval of body shape has been suggested as a major activity barrier for obese adults $(14,15)$, and both young and old obese women have been found to experience higher levels of social physique anxiety than their normal-weight counterparts (16). Individual factors increasing social physique anxiety levels are the sensitivity and visibility of the setting, e.g. mirrors and spectators, and the perceived judgmental attitude of fellow exercisers. Studies have found that an especially difficult experience for obese adults was to exercise in the company of lean, "hard-core" gymnasium members $(14,15)$. Bain et al. (14) studied obese women using qualitative methodology and found that obese women reported feeling more comfortable exercising in a group of similarly-sized people.

Treasure and colleagues (16) found a correlation ( $r=-0.37)$ between baseline social physique anxiety and treatment adherence in obese women (BMI $33.4 \pm 7.2$; age $37.7 \pm 13.8$ ) during a twelve-week walking scheme in a highly visible university setting. Interestingly, this study found no predictive value in fitness, resting heart rate, BMI, and body fat for physical activity adherence. Nevertheless, physical activity for the purpose of losing weight can be discouraging, and some argue that many obese people may benefit from decreased focus on weight loss and appearance, and instead focus on the attainment of health benefits (17).

\section{Motivation}

Motivation is often cited as important for successful physical activity behaviour change (18), yet none of the studies we reviewed measured motivation for physical activity as a study endpoint. Various techniques can be used to increase motivation, such as motivational interviewing (19). Mainly used in the addictions field, this technique tries to increase motivation by encouraging the patient to identify their own reasons for change, and by specifically addressing the patient's own agenda. Eaton et al. (20) studied physical activity involvement over time and found that the belief that physical activity prevents ill health, such as stroke, cardiovascular disease and weight gain, were significant reasons for choosing to remain active. Motivation can also be enhanced by receiving support and encouragement from other people, such as exercise leaders and peers $(14,15,21)$.

\section{Behavioural and social influences on physical activity adherence \\ Activity self-monitoring}

Incremental goal setting and self-monitoring are well-established behavioural strategies for achieving and maintaining behaviour change (22-24). Daily physical activity self-monitoring can be done in several ways, for example by using electronic step-counters (25), where the daily number of walked steps can easily be monitored in a diary or a graph. A recent study by Boutelle et al. (26) on weight gain prevention found that rigorous and frequent dietary and exercise self-monitoring helped prevent weight gain relapses during the Christmas season.

\section{Social support}

Social support is a known predictor of physical activity adherence $(22,27)$ and long-term weight loss maintenance $(28)$. An interesting study by Kayman et al. (28) investigated behavioural aspects of weight loss maintenance and weight regain in American women. Successful weight loss maintainers and normal-weight control subjects used available social support significantly more (70 and $80 \%$, respectively) than women who relapsed (38\%). Similarly, a study by Fox and colleagues (21) on GP referral for physical activity in middle-aged people in England found that being physically active in the company of friends and other social groups was a critical self-reported factor for motivation and adherence, especially for women.

Gillett (15) investigated self-reported exercise adherencerelated factors in obese women during a short (16 weeks) group exercise programme. Interviews revealed that social support from fellow obese exercisers and a health educated and sympathetic exercise leader was a major contributing factor for continued adherence.

The weight loss maintenance programme evaluated by Perri et al. (24) consisted of biweekly peer support, weekly written or telephone support from therapists and self-monitoring (Table 1). The protocol consisted of a 20 -week weight loss programme followed by randomisation to a control group or maintenance programme. An 18-month follow-up showed that the drop in therapy adherence (including physical activity) became significant much earlier in the control group (after 3 months) compared to the intervention group (after 12 months).

Wing et al. (29) randomised 43 obese type 2 diabetics to go 
Table 1. All identified long-term (duration $>1$ year) randomised controlled intervention studies with clear cognitive/behavioural intervention elements, where the sample mean BMI was above $30 \mathrm{~kg} / \mathrm{m}^{2}$, physical activity was measured as a primary or secondary study endpoint, and where at least two forms of physical activity intervention was compared between groups.

\begin{tabular}{|c|c|c|c|c|c|}
\hline Study & Participants & $\begin{array}{l}\text { Physical activity } \\
\text { comparisons between groups }\end{array}$ & $\begin{array}{l}\text { Intervention duration } \\
\text { (baseline follow-up) }\end{array}$ & $\begin{array}{l}\text { Indication of physical } \\
\text { activity adherence }\end{array}$ & $\begin{array}{l}\text { Physical activity } \\
\text { measurement }\end{array}$ \\
\hline $\begin{array}{l}\text { Andersen et al. } \\
1999(40)\end{array}$ & $\begin{array}{l}40 \text { women } \\
\text { (BMI } 32.9 \text {; } \\
\text { age } 42.9)\end{array}$ & $\begin{array}{l}\text { 1. Structured aerobic exercise } \\
\text { 2. Moderate-intensity } \\
\text { lifestyle activity }\end{array}$ & $\begin{array}{l}16 \text { weeks } \\
\text { ( } 68 \text { weeks) }\end{array}$ & $\begin{array}{l}\text { No significant difference in } \\
\text { activity levels between } \\
\text { groups during } \\
\text { the follow-up year. }\end{array}$ & $\begin{array}{l}\text { Accelerometer } \\
\text { (lifestyle activity group) } \\
\text { Session attendance } \\
\text { (structured activity group) }\end{array}$ \\
\hline $\begin{array}{l}\text { Fogelholm et al. } \\
2000(38)\end{array}$ & 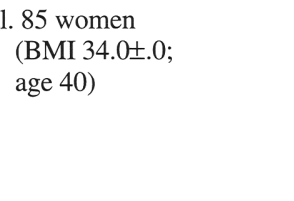 & $\begin{array}{l}\text { 1. Control } \\
\text { 2. } 4.2 \mathrm{MJ} / \text { week walking } \\
\text { programme (walk-1). } \\
\text { 3. } 8.4 \mathrm{MJ} / \text { week walking } \\
\text { programme (walk-2) }\end{array}$ & $\begin{array}{l}12 \text { weeks weight loss } \\
+40 \text { weeks weight } \\
\text { maintenance } \\
\text { ( } 1,2 \text { and } 3 \text { years, } \\
\text { respectively) }\end{array}$ & $\begin{array}{l}3040 \text { more steps/week in walk-2 } \\
\text { compared to controls after } 1 \text { year. } \\
\text { Walk-1 walked } 2570 \text { more } \\
\text { steps/week than controls after } \\
2 \text { years. 3-year group differences } \\
\text { were non-significant }\end{array}$ & Electronic pedometer \\
\hline $\begin{array}{l}\text { Jakicic et al. } \\
1999 \text { (33) }\end{array}$ & $\begin{array}{l}148 \text { women } \\
(\mathrm{BMI} 32.8 \pm 4.0 \\
\text { age } 36.7 \pm 5.6)\end{array}$ & $\begin{array}{l}\text { 1. Long exercise bouts (LB) } \\
\text { 2. Short (10-min) exercise } \\
\text { bouts }(\mathrm{SH}) \\
\text { 3. Short, multiple bouts with } \\
\text { home treadmill (SBEQ) }\end{array}$ & $\begin{array}{l}18 \text { months } \\
(6,12 \text { and } 18 \text { months, } \\
\text { respectively) }\end{array}$ & $\begin{array}{l}\text { Activity levels in SBEQ was } \\
\text { significantly better than other } \\
\text { groups during months } \\
13-18(\mathrm{p}>.05)\end{array}$ & $\begin{array}{l}\text { Questionnaire and activity } \\
\log \text { (logs were verified } \\
\text { by accelerometer) }\end{array}$ \\
\hline $\begin{array}{l}\text { Jeffery et al. } \\
1998(30)\end{array}$ & $\begin{array}{l}29 \text { men and } 167 \text { women } \\
\text { (BMI about } 31 ; \\
\text { age about } 40)\end{array}$ & $\begin{array}{l}\text { 1. } \mathrm{SBT}^{1} \\
\text { 2. Supervised group exercise+SBT } \\
\text { 3. Personal trainer+SBT } \\
\text { 4. Financial incentive+SBT } \\
\text { 5. Personal trainer+ } \\
\text { financial incentive+SBT }\end{array}$ & $\begin{array}{l}18 \text { months } \\
\text { (6 and } 18 \text { months, } \\
\text { respectively) }\end{array}$ & $\begin{array}{l}\text { No significant group } \\
\text { differences in } \\
\text { energy expenditure were } \\
\text { observed after } 18 \text { months }\end{array}$ & Questionnaire \\
\hline $\begin{array}{l}\text { Perri et al. } \\
1986(24)\end{array}$ & $\begin{array}{l}14 \text { men and } 76 \text { women } \\
(60 \% \text { over ideal weight; } \\
\text { weight } 92.1 \text {; age } 43.3 \text { ) }\end{array}$ & $\begin{array}{l}\text { Treatment: } \\
\text { 1. Behaviour therapy } \\
\text { 2. Behaviour therapy + aerobic } \\
\text { exercise. Post-treatment: } \\
\text { 3. No contact } \\
\text { 4. Multi-factorial weight loss } \\
\text { maintenance programme }\end{array}$ & $\begin{array}{l}20 \text { weeks }+12 \text {-months } \\
\text { post-treatment } \\
\text { maintenance } \\
\text { programme } \\
(3,6,12 \text { and } \\
18 \text { months, } \\
\text { respectively) }\end{array}$ & $\begin{array}{l}\text { Overall drops in therapy } \\
\text { adherence, including exercise, } \\
\text { were significant after } 3 \text { months } \\
\text { in the non-maintenance group, } \\
\text { and after } 12 \text { months in the } \\
\text { maintenance group }\end{array}$ & $\begin{array}{l}\text { Self-monitoring } \\
\text { records }\end{array}$ \\
\hline $\begin{array}{l}\text { Perri et al. } \\
1997 \text { (34) }\end{array}$ & $\begin{array}{l}49 \text { women } \\
\text { (BMI } 33.6 \pm 3.8 \text {; } \\
\text { age } 48.8 \pm 5.6 y \text { ) }\end{array}$ & $\begin{array}{l}\text { 1. Group-based exercise (GB) } \\
\text { 2. Home-based exercise (HB) }\end{array}$ & $\begin{array}{l}12 \text { months } \\
\text { ( } 6 \text { and } 12 \text { months, } \\
\text { respectively) }\end{array}$ & $\begin{array}{l}\text { HB group were more } \\
\text { active during months } \\
7-12 \text { compared to GB } \\
\text { ( } 66.2 \text { vs } 45.5 \text { minutes/week) }\end{array}$ & $\begin{array}{l}\text { Activity logs and session } \\
\text { attendance }\end{array}$ \\
\hline $\begin{array}{l}\text { Wing et al. } \\
1991 \text { (29) }\end{array}$ & $\begin{array}{l}43 \text { type II diabetics } \\
\text { (BMI about } 36 ; \\
\text { age about } 52 \text { ) }\end{array}$ & $\begin{array}{l}\text { 1. } 20 \text {-week weight control } \\
\text { programme, including } \\
\text { exercise (WCP) (alone) } \\
\text { 2. WCP + spouse support } \\
\text { (together) }\end{array}$ & $\begin{array}{l}20 \text { weeks ( } 20 \text { and } \\
72 \text { weeks, } \\
\text { respectively) }\end{array}$ & $\begin{array}{l}\text { No significant group differences } \\
\text { in exercise energy expenditure } \\
\text { between groups after } 72 \text { weeks }\end{array}$ & Questionnaire \\
\hline
\end{tabular}

$\mathrm{SBT}^{1}=$ Standard behaviour theapy

through a 20 -week weight loss programme either alone (alone condition) or to complete the programme with their spouse (together condition) and trained in providing and asking for social support (Table 1). Participants were followed-up one year from programme completion. Drop-out differences were nonsignificant $(1 / 25$ for the alone group vs $5 / 24$ for the together group, $\mathrm{p}<.09$ ), as was kilocalories spent in exercise/week. Although the role of spouse support was inconclusive for increasing energy expenditure, weight loss data revealed spouse support to have greater impact in women compared to men. Men in the alone condition lost and maintained weight loss better than men with spouse support.

The study by Jeffery et al. (30) evaluated the role of personal trainers and financial incentives to improve physical activity adoption and adherence (Table 1). Twenty-nine men and 167 women were randomised to 5 different treatment conditions: Standard Behaviour Therapy (SBT), SBT with group exercise, SBT with increased physical activity cue-reinforcement through a personal trainer who scheduled and supervised three weekly walks, SBT with group exercise and financial incentives, and the last group who received all of the above-described conditions. All five groups expended $>1000 \mathrm{kcal} /$ week in physical activity at an 18-month follow-up, with no significant group differences, despite significantly higher attendance rates at exercise sessions for the groups with personal trainers.

\section{Prompts}

Research suggests that behaviour may be influenced by prompts, for example reminders such as hints or telephone calls or starting a physically active occupation (31,32). Other examples of prompts are to establish set routines for physical activity, such as walking the dog or accompanying the children on their walk to school, or by transporting yourself in a physically active way (31).

\section{Environmental influences on physical activity adherence}

There are good indications that the environment influences physical activity behaviour change. A recent well-designed, eighteen-month, randomised controlled trial by Jakicic et al. (33) 
investigated the effect of short intermittent bouts and access to home exercise equipment on physical activity adherence, weight loss and fitness in obese, sedentary women (Table 1). Three groups were compared with different physical activity instructions, but with identical weekly volumes, 1) one continuous bout of 20-40 $\mathrm{min}$ on $5 \mathrm{~d}$ /week), 2) multiple 10-minute bouts, and 3) 10-minute bouts with home access to a treadmill. After 18 months, the short-bout group with treadmill access had significantly higher activity levels, weight loss maintenance and fat loss compared to the other groups, with no significant betweengroup differences in $\mathrm{VO}_{2}$-max.

Another interesting and well-designed intervention study by Perri et al. (34) compared participation rates in either a homebased walking programme or a group-based walking programme in a sample of forty-nine obese women enrolled on an obesity behaviour modification programme (Table 1). After six months both groups walked for the same amount of minutes $(104 \mathrm{~min} /$ week). A 12-month follow-up revealed that the home-based group had better activity maintenance compared to the groupbased group (66.2 $\mathrm{min} /$ week vs $45.4 \mathrm{~min} /$ week, respectively). The home-based group also had lower drop-out rates (1/24 vs $7 /$ 25 after 12 months), and superior weight loss (11.65 \pm 8.99 vs $7.01 \pm 8.23 \mathrm{~kg}$ after 15 months).

Other well-designed intervention studies in overweight populations (BMI $25-30 \mathrm{~kg} / \mathrm{m}^{2}$ ) have also found home-based exercise to be more effective than group-based exercise for increasing activity adherence $(35,36)$. In addition, the efficacy of home-based exercise schemes may be further improved by social support schemes, which includes telephone support, selfmonitoring, and relapse prevention strategies $(24,35,36)$.

\section{Bout adaptational influences on physical activity adherence}

Apart from the many psychological, behavioural, social and environmental influences of physical activity, there is also research indicating that activity bout adaptations of volume, type, intensity, duration and frequency may influence behaviour change.

\section{Frequency}

Unfortunately, most physical activity-induced health benefits cannot effectively be stored, and regularity is therefore critical. Current scientific guidelines for health-enhancing physical activity by the Centers for Disease Control and Prevention (CDC) and the American College of Sports Medicine (ACSM) (37) stipulate: "The accumulation of 30 minutes or more of moderate-intensity physical activity (e.g. brisk walking or stair climbing) on most, preferably all, days of the week.' It is likely that most patients will initially be unable to comply with these recommendations, yet what seems important is that patients can eventually become comfortable with physical activity, and that physical activity builds into a regular habit (23).

\section{Volume}

Fogelholm et al. (38) compared health benefits and physical activity adherence from different volume walking programmes (Table 1). Eighty-five Finnish female obese women were randomised into three groups, 1) control (no exercise), 2) walk-1 a walking programme equivalent to $4.2 \mathrm{MJ} /$ week (2-3 hours walking/week), or 3) walk-2: a walking programme equivalent to $8.4 \mathrm{MJ} /$ week (4-6 hours walking/week). Participants in the walk-1 and walk-2 groups were instructed to walk at an intensity of $50-60 \%$ of heart rate reserve. A two-year follow-up revealed that the walk-1 group walked significantly more than the walk- 2 and control group. There were no significant differences in daily walked steps between all groups after three years. These findings suggest that a moderate volume walking programme (2-3 hours/ week), may be more adherence-conducive, than a high volume walking programme (4-6 hours/week) in obese women.

\section{Intensity}

Considering the poor physical work capacity/kg in the obese, almost any activity will initially be strenuous. High-intensity physical activity $\left(>70 \%\right.$ of $\left.\mathrm{VO}_{2}-\mathrm{max}\right)$ is likely to cause physical distress, with symptoms such as joint pain, breathlessness and fatigue (23), and may not be necessary improve health more than moderate-intensity physical activity $\left(40-70 \%\right.$ of $\mathrm{VO}_{2}$-max) $(39,40)$. Indeed, high intensity activities may even be harmful in patients with cardiovascular abnormalities. Interestingly, a study by Weyer et al. (41) found that a message of moderate intensity activity (30 min of moderate intensity activities on most days of the week) was more readily accepted by obese patients (BMI $38.1 \pm 6.0 \mathrm{~kg} / \mathrm{m}^{2}$; age $45.6 \pm 13.1 \mathrm{y}$.) than higher intensity activity messages (20-60 min vigorous exercise at least three times per week).

\section{Duration}

Several well-designed intervention studies in obese adults indicate that physical activity taken in short (10-15 minutes), intermittent bouts (more than once per day) is more conducive to physical activity participation than longer formats of activity (40 minutes) $(33,42)$. The reason for this was unclear and the best activity adherence was seen in those participants who in addition to the short-bout prescription also had access to a home treadmill. No significant difference in activity participation was seen between the long-bout and short-bout groups after eighteen months (33).

\section{Type}

Non-weight bearing activities, such as resistance training, aqua aerobics, cycling, swimming and callisthenics, may be used when the ratio of physical work capacity/kg is poor. This will often be the case in the initial phase of a weight loss programme, in older patients, or in those with more severe degrees of obesity (43). Thereafter, depending an individual capacity and preferences, a gradual introduction to weight bearing activities, such as walking (using ski poles, if preferred) and aerobics may be introduced.

Although the evidence is relatively weak a small study by Thompson and Wankel (44) showed that female health club members who exercised according to their preferences had better adherence at a 6-week follow-up compared to women who were not given a choice. An Australian survey by Booth and colleagues (45) on physical activity preferences in sedentary adults found that walking followed by swimming were the most preferred activities. Walking and swimming were also found in a recent English survey by Thompson and Thomas (46) of obese patients attending a dietetic clinic to be the most popular, followed by cycling, aerobics, gym exercise, and aqua aerobics. These authors, however, noted some important gender differences. Swimming was significantly more popular amongst women as was aerobics and aqua aerobics, whereas no significant gender differences were found for walking, cycling or gymnasium exercises. The authors also argued that the activities preferred by men, walking and cycling, may reflect a general dislike for group-based physical activity.

Another emerging and promising type of activity is "lifestyle' physical activity. Dunn et al. (47) defined this as: "the daily accumulation of at least 30 minutes of self-selected activities, which includes all leisure, occupational, or household activities 
that are at least moderate to vigorous in their intensity and could be planned or unplanned activities that are part of everyday life'. This kind of activity prescription will allow more individuallyadapted activities, which has been suggested as beneficial for activity adherence $(38,41)$.

Andersen et al. (40) randomised forty sedentary, obese women to either a programme of structured exercise programme or a lifestyle-oriented exercise programme (Table 1). The structured group had three weekly aerobic step dance sessions, which increased gradually in intensity and duration. The lifestyle group self-monitored their exercise and were encouraged to exercise at a moderate intensity in short bouts as a routine part of their day. A follow-up after sixty-four weeks revealed that activity level and drop-out, cardiovascular risk factors and fat loss were similar between groups.

\section{Suggestions for study design improvements and future research areas}

The reviewed evidence was with a few exceptions inconclusive, but also lacking in important design considerations (short duration, small sample sizes, lack of randomisation, lack of control participants, lack of evidence-based explanations for magnitude and duration of behaviour change, self-report measures of physical activity, and lack of intervention foundation in behaviour change theory), which limit our conclusion confidence. As an illustration, we specifically reviewed the design and presentation of the seven long-term physical activity intervention studies shown in Table $1(24,29,30,33,34,38,40)$.

The following areas were scrutinised:

a) quality and presence of intervention description,

b) intervention foundation in behaviour change theory,

c) behaviour change process evaluation

(an evidence-based explanation for magnitude

and duration of behavioural response), and

d) physical activity measurement protocol.

Our findings were that intervention contents were often poorly described, and not one study evaluated the combined impact of standard cognitive/behavioural therapy and contemporary behaviour change theories, such as the transtheoretical model (48) or social cognitive theory (12).

Four out of the seven studies could not provide an evidencebased indication for magnitude and duration of behavioural response, and seldom was more than one such factor reported (treatment attendance and self-management techniques were the most commonly mentioned). Not one of these studies reported if the intervention actually increased psychosocial predictors of behaviour change, such as self-efficacy or social support. The majority of studies (5/7) assessed physical activity during short selected periods using self-report measures, as opposed to using objective measurement techniques (accelerometers, pedometers).

Moreover, there was only limited evidence to suggest that these studies had explicitly incorporated best known principles of behaviour change into their study design. A major implication of this last finding is that it becomes difficult to ascertain the true efficacy, as opposed to effectiveness, of physical activity in health improvements for the obese, including weight management, given the generally poor behavioural compliance to physical activity. Cultural differences may also weaken the external validity of most of the findings considering that the vast majority $(6 / 7)$ were from the US.

In summary, this important research area clearly needs more work if we are to improve our patients' behaviour change success rate for physical activity. Our suggestions for areas that we feel merit further research are shown in Table 2.
Table 2. Suggested areas for further research concerning influences on adherence to physical activity behaviour change in obese adults.

- The impact of interventions driven by both standard cognitive/ behaviour therapy and contemporary behaviour change models, such as the transtheoretical model and social cognitive theory

- The impact of environmental changes, both in the home and in greater society

- The long-term (>1y.) adherence to lifestyle-oriented $v s$ structured activity programmes

- Improved explanations for behaviour change response magnitude, such as treatment attendance, or changes in psychosocial variables such as self-efficacy, motivation, social support, social physique anxiety, self-esteem, self-monitoring, and perceived competence

- The delivery and composition of social support, especially for men

- Patient point of views on influences on physical activity behaviour change, for example by using in-depth interviews as a research methodology

- The behavioural impact of technical devices, such as electronic step-counters

- The adaptation and composition of individual intervention packages that aim to maximise adoption and long-term maintenance of behaviour change

- The feasibility of investigating physical activity intervention in those with more severe degrees of obesity (BMI $>35 \mathrm{~kg} / \mathrm{m}^{2}$ )

- Adherence data on resistance training programmes, with men/women comparisons.

- Long-term differences in physical activity levels from interventions aimed at reducing time spent in sedentary activities, as opposed to trying to increase time spent in moderate-intensity activities

\section{REFERENCES}

1. World Health Organisation: Obesity. Preventing and managing the global epidemic. Report of a WHO consultation on Obesity. Geneva, 3-5 June 1997. World Health Organisation: Geneva, 1997.

2. Pi-Sunyer FX: Comorbidities of overweight and obesity: current evidence and research issues. Med Sci Sports Exerc 1999;31:S602-S608.

3. Myers A, Rosen JC: Obesity stigmatization and coping: Relation to mental health symptoms, body image, and self-esteem. Int J Obes 1999;23:221-30

4. Caspersen CJ, Powell KE, Christenson GM: Physical activity, exercise, and physical fitness: definition and distinction for health-related research. Publ Health Rep 1985; 100:126-31.

5. Fogelholm M, Kukkonen-Harjula K: Does physical activity prevent weight gain - a systematic review. Obes Reviews 2000;1:95-111.

6. Garrow JS, Summerbell CD: Meta-analysis: effects of exercise, with or without dieting, on the body composition of overweight subjects. Eur J Clin Nutr 1995;49:1-10.

7. Fox KR: The influence of physical activity on mental well-being. Publ Health Nutr 1999;2:411-8.

8. Blundell JE, King NA: Physical activity and regulation of food intake: current evidence. Med Sci Sports Exerc 1999;31:S573-83.

9. Wei M, Kampert JB, Barlow CE, Nichaman MZ, Gibbons LW, Paffenbarger Jr RS, Blair SN: Relationship between low cardiorespiratory fitness and mortality in normal-weight, and obese men. JAMA 1999;282:1547-53.

10. Rissanen A, Fogelholm M: Physical activity in the prevention and treatment of other morbid conditions associated with obesity: current evidence and research issues. Med Sci Sports Exerc 1999;31:S635-S645.

11. McAuley E, Courneya KS, Rudolph DL, Lox CL: Enhancing exercise adherence in middle-aged males and females. Prev Med 1994;23:498-506.

12. Bandura A: Social foundations of thought and action. Englewood Cliffs, NJ: Prentice Hill, 1986.

13. Pinto BM, Clark MM, Cruess DG, Szymanski L, Pera V: Changes in selfefficacy and decisional balance for exercise among obese women in a weight management program. Obes Res 1999;7:288-92.

14. Bain LL, Wilson T, Chaikind E: Participant perceptions of exercise programs for overweight women. Res Q Exerc Sport 1989;60:134-43.

15. Gillett PA: Self-reported factors influencing exercise adherence in overweight women. Nursing Res 1988;37:25-9.

16. Treasure DC, Lox CL, Lawton B: Determinants of physical activity in a sedentary, obese female population. J Sport Exerc Psychol 1998;20:1-6.

17. Lyons P, Miller WC: Effective health promotion and clinical care for large people. Med Sci Sports Exerc 1999;31:1141-6.

18. Baranowski T, Anderson $\mathrm{C}$, Carmack $\mathrm{C}$ : Mediating variable framework in physical activity interventions. How are we doing? How might we do better? Am J Prev Med 1998;15:266-97. 
19. Rollnick S: Behaviour change in practice: targeting individuals. Int J Obes 1996;20:S22-S26.

20. Eaton CB, Reynes J, Assaf AR, Feldman H, Lasater T, Carleton RA: Predicting physical activity change in men and women in two New England communities. Am J Prev Med 1993;9:209-19.

21. Fox KR, Biddle S, Edmunds LE, Killoran A, Bowler I: Physical activity promotion through primary health care in England. Br J Gen Pract 1997;47: 367-9.

22. Biddle SJH, Fox KR: Motivation for physical activity and weight management. Int J Obes 1998;22:S39-S47.

23. Fox KR: A clinical approach to exercise in the markedly obese. In: Wadden TA, VanItallie TB (eds). Treatment of the seriously obese patient. Guildford press: London, 1992, pp 354-382.

24. Perri MG, Lauer JB, McAdoo WG, McAllister DA, Yanzey DZ: Enhancing the efficacy of behavior therapy for obesity: effects of aerobic exercise and a multicomponent maintenance program. J Consult Clin Psychol 1986; 54:670-5.

25. Leenders NYJM, Sherman WM, Nagaraya HN: Comparisons of four methods of estimating physical activity in adult women. Med Sci Sports Exerc 2000;32:1320-6.

26. Boutelle KN, Kirschenbaum DS, Baker RC, Mitchell ME: How can obese weight controllers minimize weight gain during the high risk holiday season: by self-monitoring very consistently. Health Psychol 1999;18:364-8.

27. Sallis JF, Owen N: Physical activity and behavioral medicine. Sage publications: Thousand Oaks, 1999.

28. Kayman S, Bruvold W, Stern JS: Maintenance and relapse after weight loss in women: behavioural aspects. Am J Clin Nutr 1990;52:800-7.

29. Wing RR, Marcus MD, Epstein LH, Jawad A: A "family-based" approach to the treatment of obese type II diabetic patients. J Consult Clin Psychol 1991;59:156-62.

30. Jeffery RW, Wing RR, Thorson C, Burton LR: Use of personal trainers and financial incentives to increase exercise in a behavioural weight-loss program. J Consult Clin Psychol 1998;66:777-83.

31. Dishman RK: Exercise adherence: its impact on public health. Human Kinetics: Champaign, 1988.

32. Lombard DN, Neubauer Lombard T, Winett RA: Walking to meet health guidelines: the effect of prompting frequency and prompting structure. Health Psychol 1995;14:164-70.

33. Jakicic JM, Winters C, Lang W, Wing RR: Effects of intermittent exercise and use of home exercise equipment on adherence, weight loss, and fitness in overweight women. JAMA 1999;282:1554-60.

34. Perri MG, Martin AD, Leermakers EA, Notelovitz M: Effects of groupversus home-based exercise in the treatment of obesity. J Consult Clin
Psychol 1997;65:278-85.

35. King AC, Haskell WL, Taylor CB, Kraemer HC, DeBusk RF: Group-versus home-based exercise training in healthy men and women: a communitybased clinical trial. JAMA 1991;266:1535-42

36. King AC, Haskell WL, Young DR, Oka RK, Stefanick ML: Long-term effects of varying intensities and formats of physical activity on participation rates, fitness, and lipoproteins in men and women aged 50 to 65 years. Circulation 1995;91:2596-604.

37. Pate RR, Pratt M, Blair SN, Haskell WL, Macera CA et al.: Physical activity and public health. JAMA 1995;273:402-7.

38. Fogelholm M, Kukkonen-Harjula K, Nenonen A, Pasanen M: Effects of walking training on weight maintenance after a very-low-energy diet in premenopausal obese women. Arch Intern Med 2000;160:2177-84.

39. Dunn AL, Marcus BH, Kampert JB, Garcia ME, Kohl III HW, Blair SN: Comparisons of lifestyle and structured interventions to increase physical activity and cardiorespiratory fitness: a randomized trial. JAMA 1999;281: 327-34.

40. Andersen RA, Wadden TA, Bartlett SJ, Zemel B, Verde TJ, Frankowiak SC. Effects of lifestyle activity vs structured aerobic exercise in obese women. JAMA 1999;281:335-40.

41. Weyer C, Linkeschowa R, Heise T, Giesen HT, Spraul M: Implications of the traditional and the new ACSM physical activity recommendations on weight reduction in dietary treated obese subjects. Int J Obes 1998;22:1071-8.

42. Jakicic JM, Wing RR, Butler BA, Robertson RJ: Prescribing exercise in multiple short bouts versus one continuos bout: effects on adherence, cardiorespiratory fitness, and weight loss in overweight women. Int J Obes 1995; 19:893-901

43. Mattsson E, Evers Larsson U, Rössner S: Is walking for exercise too exhausting for obese women? Int J Obes 1997;21:380-6.

44. Thompson CE, Wankel LM: The effects of perceived activity choice upon frequency of exercise behaviour. J Appl Soc Psychol 1980;10:436-43.

45. Booth ML, Bauman A, Owen N, Gore CJ: Physical activity preferences, preferred sources of assistance, and perceived barriers to increased activity among physically inactive Australians. Prev Med 1997;26:131-7.

46. Thompson RL, Thomas DE: A cross-sectional survey of the opinions on weight loss treatments of adults obese patients attending a dietetic clinic. Int J Obes 2000;24:164-70.

47. Dunn AL, Andersen RE, Jakicic JM: Lifestyle physical activity interventions: history, short- and long-term effects, and recommendations. Am J Prev Med 1998;15:398-412.

48. Prochaska JO, DiClemente CC: Stages and processes of self-change in smoking: toward an integrative model. J Consult Clin Psychol 1983:51: 390-5. 